\title{
Optimizing Effective Absorption during Wet Natural Gas Dehydration by Tri Ethylene Glycol
}

\author{
Khan, Mohd Atiqueuzzaman; Maruf, ASM
}

\begin{abstract}
Effective dehydration of sales gas is the primary concern before its transmission over a long distant pipeline. The most common and efficient dehydration system is based on the counter-current absorption by TEG (Tri Ethylene Glycol). This paper deals with the problems that generally occur during the dehydration process. In a mission to find out the optimization for a troubled and unstable TEG dehydration system, this paper describes some common problems such as inappropriate TEG circulation rate, deposition waxy material formation in the internal tray assembly, higher hydrocarbon content in rich TEG, TEG loss and the solutions have been discussed with results. A simulator has been used to find out some results theoretically. Finally there were some recommendations to avoid additional problems in dehydration.
\end{abstract}

\section{Introduction}

The last 35 years have seen a remarkable growth in the contribution of gas to the world's total primary energy demand. Almost every country in the south Asia are dependent on the natural gas as it satisfies the majority if the country's demand. Natural gas from production is generally associated with crude oil and water. In a natural gas processing plant, the primary separation is occurred in the 3 phase high pressure separator where natural gas, condensate, and water are separated. However, after the primary separation substantial amount of water remains present in the wet gas that needs to be dehydrated further. It is necessary to prevent the condensation of liquid water and hydrocarbons to ensure trouble-free operation of a natural gas transmission system.

There is always a risk of hydrate formation which eventually results condensate accumulation in pipeline and increase in operating pressure. Every transmission company has a sales gas criterion that includes total liquefiable and water content in the sales. Dehydration of natural gas is the removal of the water that is associated with natural gases in vapor form.

The natural gas processing plant includes a dehydration system that could be either refrigeration system or countercurrent absorption system.

This paper deals with the dehydration system that is driven by Tri Ethylene glycol.

\section{Teg Dehydration Process}

Absorption dehydration involves the use of a liquid desiccant to remove water vapor from the gas. Although many liquids possess the ability to absorb water from gas, the liquid that is most desirable to use for commercial dehydration purposes should possess the following properties:

1. High absorption efficiency.

2. Easy and economic regeneration.

3. Non-corrosive and non-toxic.

4. No operational problems when used in high concentrations.

5. No interaction with the hydrocarbon portion of the gas, and no contamination by acid gases.

Table 1: General Physical and Chemical Properties of Glycols ${ }^{[2]}$.

\begin{tabular}{|l|l|l|l|l|}
\hline $\begin{array}{l}\text { Molecular } \\
\text { Weight }\end{array}$ & 62.1 & 106.1 & 150.2 & 194.2 \\
\hline $\begin{array}{l}\text { Boiling Point } \\
\text { @760 mm Hg, } \\
{ }^{\circ} \mathrm{F}\end{array}$ & 387.3 & 473.8 & 550.0 & 618.1 \\
\hline $\begin{array}{l}\text { Freezing } \\
\text { Point, }{ }^{\circ} \mathrm{F}\end{array}$ & 7.9 & 16.4 & 19.0 & 15.1 \\
\hline Flash Point, ${ }^{\circ} \mathrm{F}$ & 247 & 281 & 325 & 400 \\
\hline $\begin{array}{l}\text { Specific } \\
\text { Gravity@ } \\
25^{\circ} \mathrm{C}\end{array}$ & 1.110 & 1.111 & 1.120 & 1.123 \\
\hline $\begin{array}{l}\text { Vap. Pressure } \\
\left(25^{\circ} \mathrm{C}\right),\end{array}$ & $<0.1$ & $<0.01$ & $<0.01$ & $<0.01$ \\
\hline
\end{tabular}




\begin{tabular}{|l|l|l|l|l|}
\hline $\mathrm{mm} \mathrm{Hg}$ & & & & \\
\hline $\begin{array}{l}\text { Aqueous } \\
\text { Solubility }\end{array}$ & $\begin{array}{l}\text { miscib } \\
\text { le }\end{array}$ & miscible & miscible & miscible \\
\hline
\end{tabular}

The glycols, particularly ethylene glycol (EG), Di ethylene glycol (DEG), Tri ethylene glycol (TEG), and Tetra ethylene glycol (T4EG) comes to closest to satisfying these criteria to varying degrees. Water and the glycols show complete mutual solubility in the liquid phase due to hydrogen-oxygen bonds, and their water vapor pressures are very low. One frequently used glycol for dehydration is Tri ethylene glycol, or TEG, and the discussion of this paper will be limited to Tri ethylene Glycol.

\section{Process Description}

TEG-dehydration process can be divided into two major parts, gas dehydration and solvent regeneration. In dehydration, wet gas is dehydrated by countercurrent absorption process by TEG and in the regeneration, water is removed from the solvent (TEG); and after regeneration fresh (lean) TEG is fed back to contactor tower.

Generally a TEG-dehydration unit is contains: absorption column, flash tank, heat exchangers, inlet scrubber and regenerator, (Figure 1).

During the process, fresh (lean) TEG enters to the absorption column at the top side. After absorption, rich solvent is collected at the bottom of the column and enters into the regeneration system. Wet gas enters to the absorption column after passed through inlet scrubber (optional). In most cases using an inlet scrubber is optional, as it solely depends on the amount of the liquid present in the wet gas. The scrubber removes free liquid and liquid droplets in the gas, both water and hydrocarbons the scrubber decreases the amount of water that has to remove in the absorption column, and this also decreases the size of the column and therefore decrease the TEG needed in process.

For effective dehydration process ${ }^{[4]}$ the temperature difference between the two streams should be around 10 15 degree. The hot lean TEG fed to the contactor column generally have a higher temperature that needs to be reduced and a gas glycol exchanger is used where the lean TEG exchanges heat with the gas outlet from the Contactor tower.

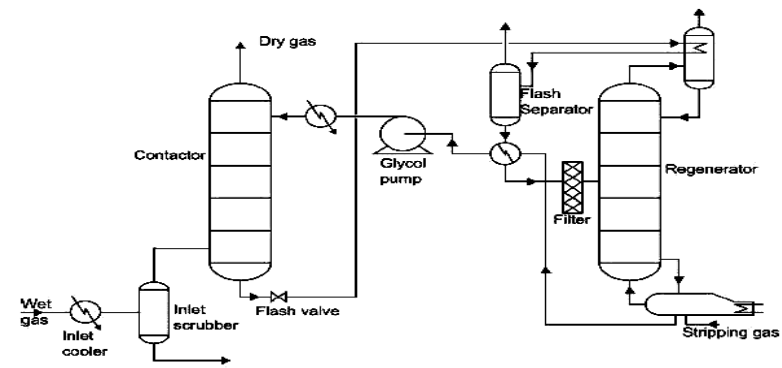

Figure 1: Typical Gas dehydration system ${ }^{[1]}$

The flash tank used for removal of absorbed acidic gases and higher hydrocarbons in TEG before rich solvent enter to the regenerator, which is a distillation column, and separate the TEG and water content. Of rich TEG is preheated in another heat exchanger before it fed to the regeneration section. The regenerated lean TEG then exchanges heat with incoming rich stream that eventually decreases its temperature. And finally the lean TEG is fed to the contactor tower.

The glycol rate out of the Glycol Contactor is controlled by a level control valve and the inlet flow rate of glycol is determined the TEG pump discharge. The glycol temperature returning from the regeneration skid is monitored. The temperature of the dehydration system varies at a close range from 100 to $140 \mathrm{Deg} F$. The differential pressure across the contactor packing section is monitored and a high differential pressure alarm refers blockage of the packing structure. The dew point of the outlet gas from the contactor tower is monitored through a moisture analyzer.

\section{Common Process Troubleshooting}

Off-spec moisture could be caused by:

Countercurrent absorption process by Tri ethylene glycol depends on certain process parameters ${ }^{[5]}$ :

1. TEG circulation rate.

2. High pressure separator equilibrium conditions

3. Inlet Gas temperature

4. Differential pressure of the contactor column. 
5. Striping Gas flow rate

6. Hydrocarbon flushing on the flash separator.

\section{TEG Circulation Rate}

Various studies have been made about the TEG water equilibrium and the actual circulation rate that is naturally required for any design process may still vary. However, the circulation rate can be calculated with the aid of different equations ${ }^{[3]}$ :

The basic absorption equation may be written as:

Where,

$$
\text { Absorption Efficiency, } E_{a}=\frac{y_{n+1}-y_{1}}{y_{n+1}-y_{0}}
$$

$\mathbf{y}_{\mathbf{N}+1}==$ Mole fraction of water in entering wet gas

$\mathbf{y}_{\mathbf{1}}=$ Actual mole fraction of water in dried gas leaving

$\mathbf{y}_{\mathbf{0}}=$ Water content of dried gas if it is equilibrium with the entering glycol

$\mathbf{A}=$ Absorption Factor

$\mathbf{L}=$ glycol Circulation rate

$\mathbf{V}=$ Gas flow rate

$\mathbf{N}=$ Number of theoretical plates in the absorber

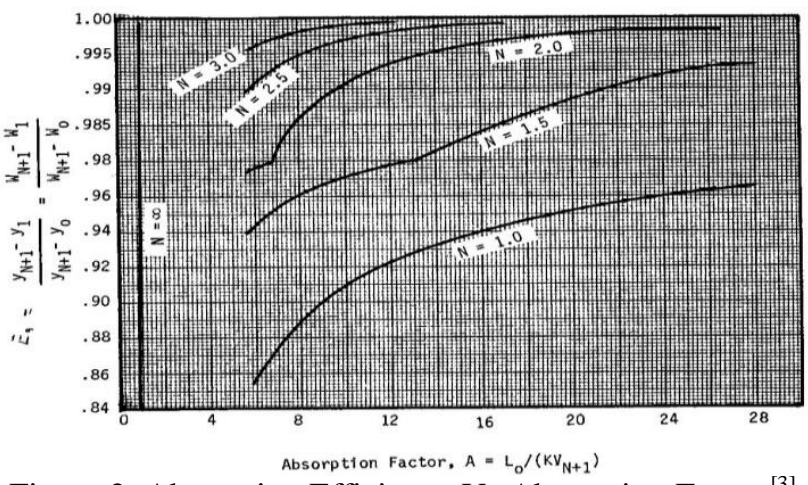

Figure 2: Absorption Efficiency Vs Absorption Factor ${ }^{[3]}$

The equilibrium relationship of water with the TEG can be calculated with the aid of activity coefficient. The reliable method for calculating the equilibrium constant $(\mathrm{K})$ of TEG water system is,

Here,

$$
K=\left(Y_{w}\right)(\gamma)=B W(\gamma)
$$

$\mathbf{y}_{\mathbf{w}}=$ Mole fraction of water at saturation over $100 \%$ liquid

$\gamma=$ activity coefficient for water in the TEG-water system

$\mathbf{W}=$ Water content on a mass per volume basis, at saturation

$\mathrm{B}=1.33(\mathrm{E}-06)$ When $\mathrm{W}=\mathrm{Kg} / 106 \mathrm{std} / \mathrm{m} 3$

$\mathrm{B}=2.11(\mathrm{E}-05)$ When $\mathrm{W}=\mathrm{lbm} / \mathrm{MMSCF}$

An average $\mathrm{K}$ at average concentration cannot be found until the circulation rate is fixed, so a simple trial and error method is involved. For most dehydration applications the increase in $\mathrm{K}$ from the lean to rich TEG is proportional to the increase in $\mathrm{L} / \mathrm{V}$, so the absorption factor, $\mathrm{A}=\mathrm{LV} / \mathrm{K}$ is unchanged.

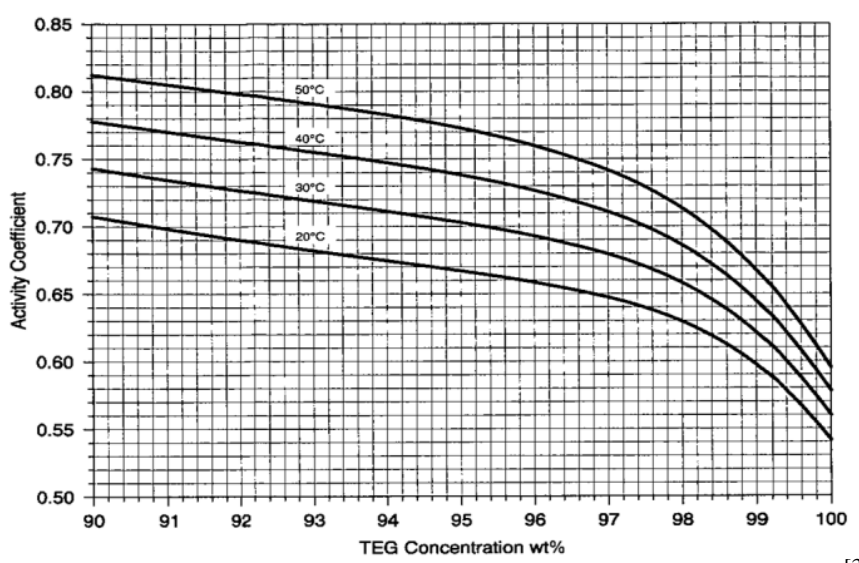

Figure 3: Activity coefficient for various TEG concentrations ${ }^{[3]}$ 
For a given circulation rate, the values of inlet and outlet water content, gas flow rate absorber pressure is fixed. Using a correlation for determining the $\mathrm{K}$ value of water in a TEG water system, values for $\mathrm{y}_{0}$ and $\mathrm{K}$ are available. Hence the TEG circulation rate $\mathrm{L}$ can be calculated when the value of $\mathrm{N}$ is known.

\section{Test Conditions ${ }^{[7]}$ :}

The effect of process parameters have been studied in a typical gas processing plant in Bangladesh. Sweet natural gas is feed to the contactor designed for 200 MMSCFD and the operating pressure was 1150 Psi.

The carbon steel contactor sizing is 19'-4'"( $\left.460 \mathrm{ft}^{3}\right)$ with $316 \mathrm{~L}$ SS Packing With Chimney Tray having four 12 " pipes.

Glycol circulation rates have been tested in different inlet gas temperatures and reboiler operating conditions:

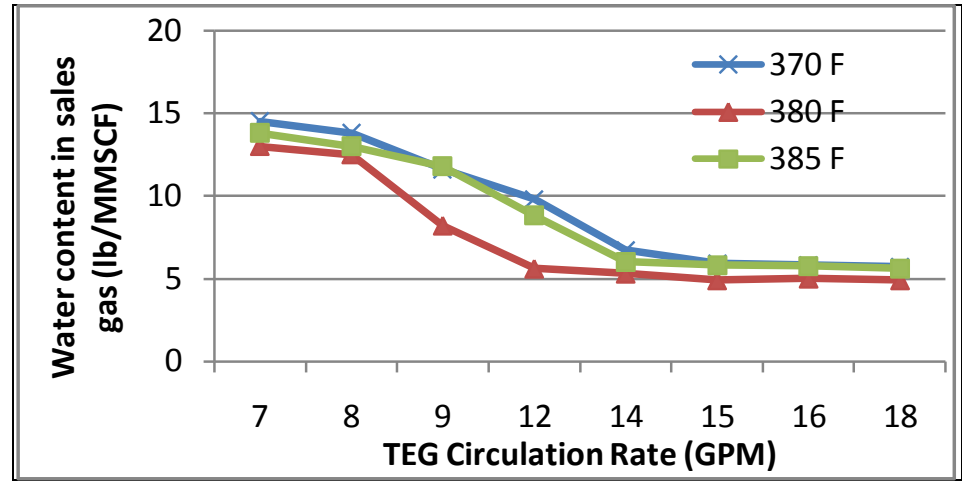

Figure 4: Water content VS circulation rates and reboiler Temperature ${ }^{[1 /}$

(Contactor Inlet Gas Temperature fixed at 90 Deg F)

The result clearly shows the optimum operating point of TEG reboiler points. Lower dew points have been resulted TEG reboiler is operated in 380 degree $\mathrm{F}$. The optimum circulation rates under the operating conditions are also evident in the result. It is certain that under the design condition, lowest dew point refers the corresponding circulation rate somewhere between 14 and 15 GPM.

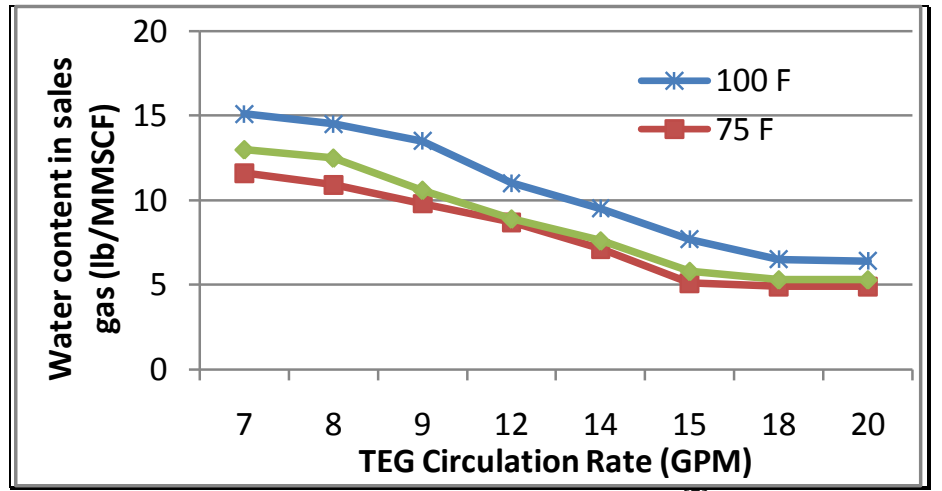

Figure 5: Water content VS circulation rates and inlet gas temperature ${ }^{[7]}$ (Reboiler Operating Temperature 380 Deg F)

Another graph has been plotted based on the inlet gas temperatures of the contactor. The results clearly show that lower inlet gas temperature to the contactor requires less amount of TEG circulation. However it will be more clear if there were another graph representing the experimental results under 75 Deg $\mathrm{F}$ but due to the raw gas temperature. The results are limited to the value of 75 degree $F$.

Flow direction and settling time are directly related to the water content in the wet gas from the high pressure separator. The following graph contains results on two different equilibrium conditions. Initially the high pressure separation was designed to handle 200 MMSCFD of sweet natural gas with and operating pressure of 1120 psig. Later a cyclone separator has been installed to increase the settling time and flow direction of the inlet fluid. Lab results confirm that initially HP separator outlet gas stream contained around $40 \mathrm{lb} / \mathrm{MMSCF}$ and after medication the amount came down to $31 \mathrm{lb} / \mathrm{MMSCF}$. As the inlet water content decreases due to the equilibrium condition, lower dew points have been observed in same TEG circulation rates. 


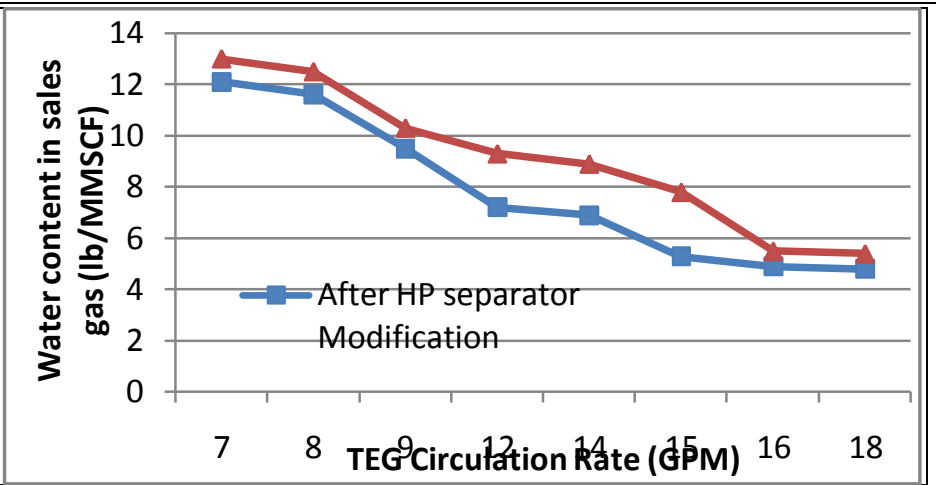

Figure 6: Water content VS circulation rates in different settling time ${ }^{[7]}$

\section{Stripping Gas In The Reboiler}

Stripping gas flow rate is actually a parameter in the stripping column of TEG regeneration system, which is a function with the reboiler efficiency.

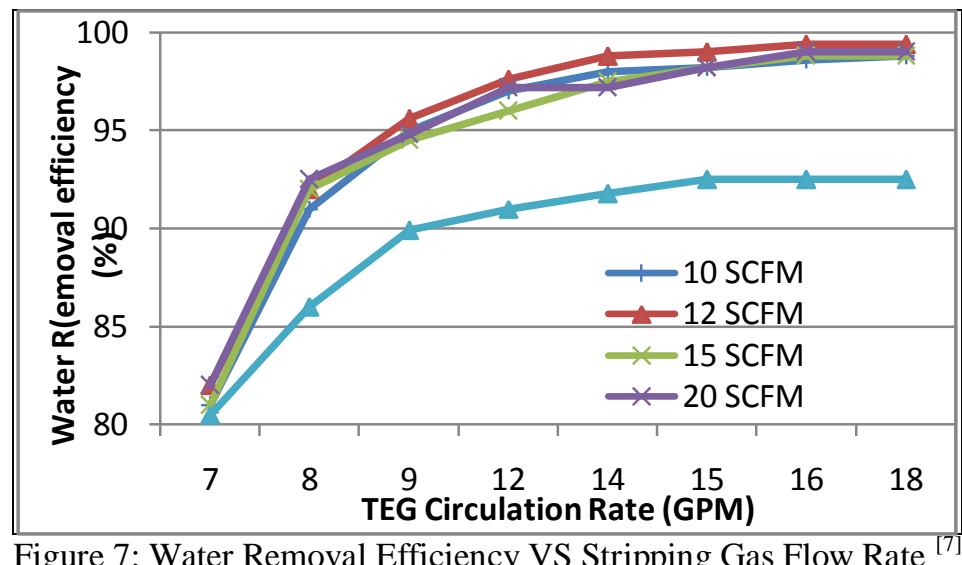

We have tested different stripping rate conditions of the reboiler and calculated the water removal efficiency from the rich glycol at given circulation rates. As countercurrent absorption in contactor is directly dependant on the quality of the lean TEG fed to the contactor, higher efficiency of water removal (more than $99 \%$ ) is one of the main areas of concern in optimization of this process.

\section{Differential Pressure of the Contactor Column}

The differential pressure across the packing of the contactor indicates the proper passage for liquid and gas flow. Higher hydrocarbon content present in the wet gas of contactor inlet leads to the deposition of some waxy materials or sludge that eventually increase the PDI across the packing of the contactor. As a result the TEG cannot be distributed equally as less amount of surface area is exposed to the contact with wet gas.

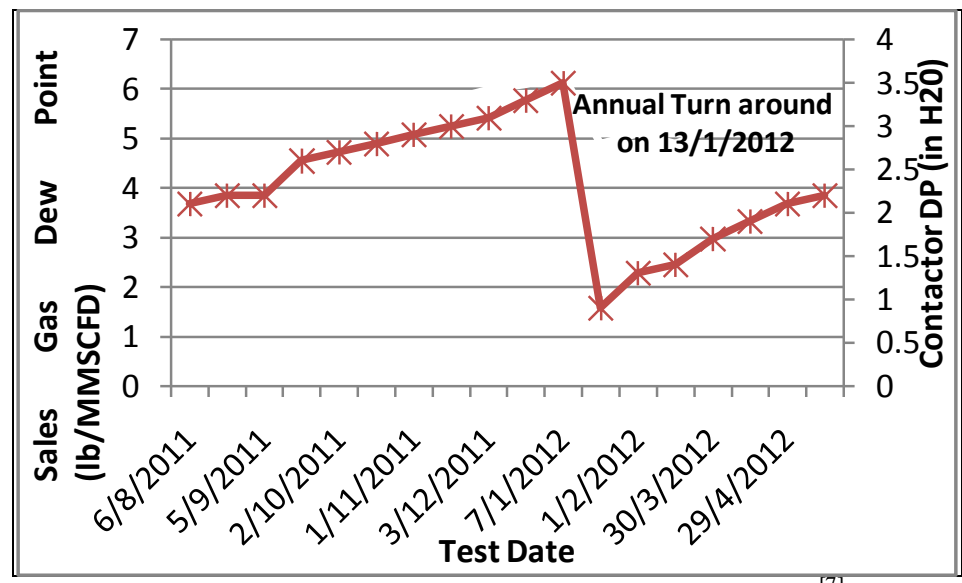

Figure 8: Sales Gas Dew Point Vs. Contactor DP ${ }^{17}$ 
An investigation was carried out and showed some interesting results. Each year before turn around job, gas flow is cut from the contactor and TEG with a relatively higher temperature ( 150 Deg F) from the TEG accumulator has been fed to the contactor. After turn around job the dew point improves significantly as the contactor DP also decreases. This evidence refers to the hypothesis that the deposited materials that have been suspected to be responsible for increasing the contactor DP, has been washed away by the hot TEG circulation after the gas flow was cut. Therefore, circulating hot TEG in higher temperature is a practical solution for a troubled dehydration system that has high DP across the contactor tower.

\section{Hydrocarbon Flushing On Flash Separator}

Considerable amount of hydrocarbon are present in the rich TEG that are required to be separated before the Rich TEG enters into the regeneration system.

A low pressure flushing process is followed by the dehydration process, where higher hydrocarbons turn into liquid and are separated from the rich TEG using the differences of their specific gravity. Flushing operation could be carried out manually or automatically, but the amount of natural gas condensate collected from the flush tank ensures the efficiency of the regeneration system. During normal process operation, different amount of hydrocarbons were drained from the flash separator and the effect of change in the amount of collected hydrocarbons clearly stated the stability of the regeneration system.

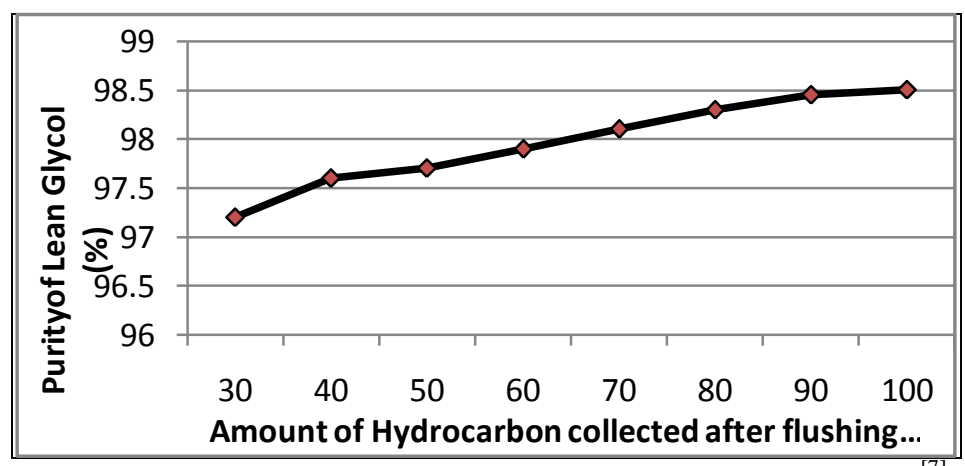

Figure 8: Purity of Lean Glycol in different Flushing Efficiency ${ }^{[7]}$

\section{Conclusion}

Experimental results are based on certain operating conditions, however it provides the trend of the data and any proactive action could be taken following the results on the experimental conditions. There is still some confusion about the required TEG circulation rates for the absorber as the tray efficiency of the absorber do not remain the same. Another point is the idea about the contactor DP still demands more experimental evaluation and solubility of the waxy materials could be tested with some other components such as diesel or natural gas condensate. The amount collected hydrocarbons actually depends on the composition of the raw gas and that can significantly vary with the other regions of the world. Some others idea about modifications of high pressure separator still demands further research options for obtaining maximum velocity diversion and settling time.

Experiments to determine effect of one parameter were carried out keeping the other ones fixed based on the optimum operative conditions. But the experiments have limitations as natural gas with different compositions were not tested for dehydration. Perhaps a process simulator could be used to carry out more a more comparative approach in this regard.

\section{Reference}

[1]. Polak, L.: Modeling absorption drying of natural gas, NTNU, May 2009.

[2]. Perry, R.H., Green, D.W.: Perry's chemical engineer's handbook, 8th ed., McGraw-Hill, 2007.

[3]. Campbell, J.M.: Gas conditioning and processing, vol. 2, CPS, 1982.

[4]. Guo,B., Ghalambork,A.: Natural gas engineering handbook, Gulf Publishing Co.,2005.

[5]. P. Gandhidasan, Parametric Analysis of Natural Gas Dehydration by a Tri ethylene Glycol Solution, energy Sources,25:189-201

[6]. Kazemi P., Hamidi R: Sensitivity analysis of a natural gas Try ethylene glycol dehydration plant in Persian gulf region, Petroleum \& Coal 53 (1) 71-77, 2011.

[7]. Process operation data, Titas Gas plant Bangladesh, July 2011- August 2012 